\title{
IX. The structure of silver crystals
}

\section{Vegard Dr.phil.}

To cite this article: L. Vegard Dr.phil. (1916) IX. The structure of silver crystals, Philosophical Magazine Series 6, 31:181, 83-87, DOI: 10.1080/14786440108635473

To link to this article: http://dx.doi.org/10.1080/14786440108635473

\section{Published online: 08 Apr 2009.}

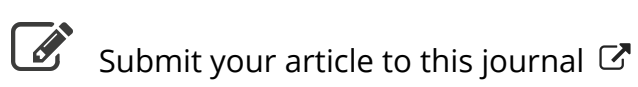

Џll Article views: 10

Q View related articles ¿

Citing articles: 15 View citing articles ¿ 
Let $\sum_{n=0}^{\infty} \frac{r^{n+a+\kappa}}{n+a+\kappa}=\mathrm{S}_{\kappa}$,

then

and

$$
\begin{aligned}
\mathrm{S}_{\kappa}=\sum_{n=a+\kappa}^{\infty} \frac{r^{n}}{n} & =\sum_{n=1}^{\infty} \frac{r^{n}}{n}-\sum_{n=1}^{a+\kappa-1} \frac{\gamma^{n}}{n} \\
& =-\log (1-r)-\sum_{n=1}^{a+\kappa-1} \frac{r^{n}}{n},
\end{aligned}
$$

But

$$
\begin{array}{r}
S=(b-a)\left(\begin{array}{l}
b-1 \\
a-1
\end{array}\right)\left[-\frac{\log (1-r)^{b-a-1}}{r^{a+1}} \sum_{\kappa=0}(-1)^{\kappa}\left(\begin{array}{c}
b-a-1 \\
\kappa
\end{array}\right) \frac{1}{r^{\kappa}}\right. \\
\left.+\frac{1}{r^{a}} \sum_{\kappa=0}^{b-a}(-1)^{\kappa}\left(\begin{array}{c}
b-a-1 \\
\kappa-1
\end{array}\right) \sum_{n=1}^{a+\kappa-1} \frac{r^{n-\kappa}}{n}\right] .
\end{array}
$$

$$
\sum_{\kappa=0}^{b-a-1}(-1)^{\kappa}\left(\begin{array}{c}
b-a-1 \\
\kappa
\end{array}\right) \frac{1}{r^{k}}=\left(1-\frac{1}{r^{r}}\right)^{b-a-1}=\frac{(r-1)^{b-a-1}}{r^{b-a-1}}
$$

Therefore

$$
\begin{aligned}
S=(b-a)\left(\begin{array}{c}
b-1 \\
a-1
\end{array}\right)[ & \frac{(-1)^{b-a} \log (1-r)}{r^{b}}(1-r)^{b-a-1} \\
& \left.+\frac{1}{r^{a}} \sum_{\kappa=1}^{b-a}(-1)^{\kappa}\left(\begin{array}{c}
b-a-1 \\
\kappa-1
\end{array}\right) \sum_{n=1}^{a+\kappa-1} \frac{r^{n-\kappa}}{n}\right]
\end{aligned}
$$

University of Penusylvania,

Philadelphia, U.S.A.

\section{The Structure of Silver Crystals.}

\section{By L. Vegard, Nr. phil., University of Christiania *}

A $\mathbf{S}$ a contribution to the study of the inner structure of $A$ crystals by the Röntgen ray analysis, I am going to give an account of the determination of the crystalline structure of silver.

Silver crystals belong to the cubic system, and are found in nature in very fine specimens of considerable size and with well-developed regular crystal-faces.

For the analysis I used the reflexion method of W. H. Bragg and W. L. Bragg $\dagger$, which is based on the determination of the reflexion angle of a homogeneous beam of X-rays.

The Röntgen-ray tube was of the sort recommended by Bragg, with a rhodium anticathode. The Röntgen-ray spectrometer was in principle the same as that constructed

* Communicated by the Author. p. 428.

† W. H. Bragg and W. L. Bragg, Proc. Roy. Soc. A. vol. lxxxviii. 
by Bragg, although the particular arrangements were somewhat different. The slits and the ionization-chamber were mounted on the top of an ordinary Fuess goniometer, in such a way that the incident beam of $X$-rays and the axis of the ionization-chamber were parallel to the axes of the collimator and telescope respectively. The optical arrangements, however, were not removed, so the instrument could at the same time be used as a goniometer.

The crystal was mounted in the usual way on the crystal table with some wax. By means of a screw underneath the instrument the table could be moved up and down without any appreciable rotation of the crystal.

This arrangement proved very convenient, as it was possible to set the crystal-face very accurately by means of the optical arrangement, and then move it upwards until its central part came into level with the axis of the ionizationchamber.

The crystals used were two fine specimens which were kindly lent me by Professor W. C. Brögger, of the Mineralogical Laboratory. The one had the cube faces (100) and the other the tetrahedron faces (111) well developed.

The crystals were good reflectors. In order that no maximum might escape notice the entire ionization curve for varying angles was determined first with fairly wide slits $(1 \mathrm{~mm}$.). Then a more accurate measurement was made of the plate given by the strongest $\mathrm{Rh}$ line of wavelength $\lambda=0.60710^{-8} \mathrm{~cm}$., using a slit about $0.4 \mathrm{~mm}$. broad.

The condition for reflexion is given by the following formula of Bragg:

$$
n \lambda=2 d \sin \theta ;
$$

$d$ is the distance from one point plane to the next identioal plane ; $\theta$ is the glancing angle of the incident beam, $\lambda$ the wave-length, and $n$ the order-number.

The zero position of the chamber, as determined from the direct beam, is perhaps less accurate than the position corresponding to maximum ionization from the reflected beam. From the position of the first and second maxima, however, we can easily calculate the true zero position and the true glancing angle $\theta$.

Let the observed angles for the 1st, 2nd, \&c. order be $\alpha_{1}, \alpha_{2}, \ldots$, and the true zero position $\alpha_{0}$, then

$$
\begin{aligned}
\theta_{1} & =\frac{\alpha_{1}-\alpha_{0}}{2}, \quad \theta_{2}=\frac{\alpha_{2}-\alpha_{0}}{2}, \quad \text { and } \\
\cot 2 \theta & =2 \operatorname{cosec}\left(\alpha_{2}-\alpha_{1}\right)-\cot \left(\alpha_{2}-\alpha_{1}\right) .
\end{aligned}
$$


For the reflexion planes (100) and (111), for which the crystal had corresponding crystal-faces, the maxima of 1st, 2nd, and 3rd order were found. The calculation gave for $\alpha_{0}$ the values $+\mathrm{l}^{\prime}$ and $-\mathrm{l}^{\prime}$ for the two faces respectively. Thus the fault in the direct determination of the zero position is practically negligible.

The crystal, however, had no marked (110) face, and to get the reflexion from these planes the cube-faced crystal was put up with the (110) plane vertical and the edge (100) horizontal. But in this way the image of the reflected beam will not be a vertical slit, but will be $(>)$ shaped, and the determination of the glancing angle less accurate. Further, the reflexion from the (110) plane was so weak that only the first maximum could be measured. But as the zero position is known, the first maximum will be sufficient for the determination of the glancing angle.

In fig. 1 is given the maxima corresponding to the strongest

Fig. 1.

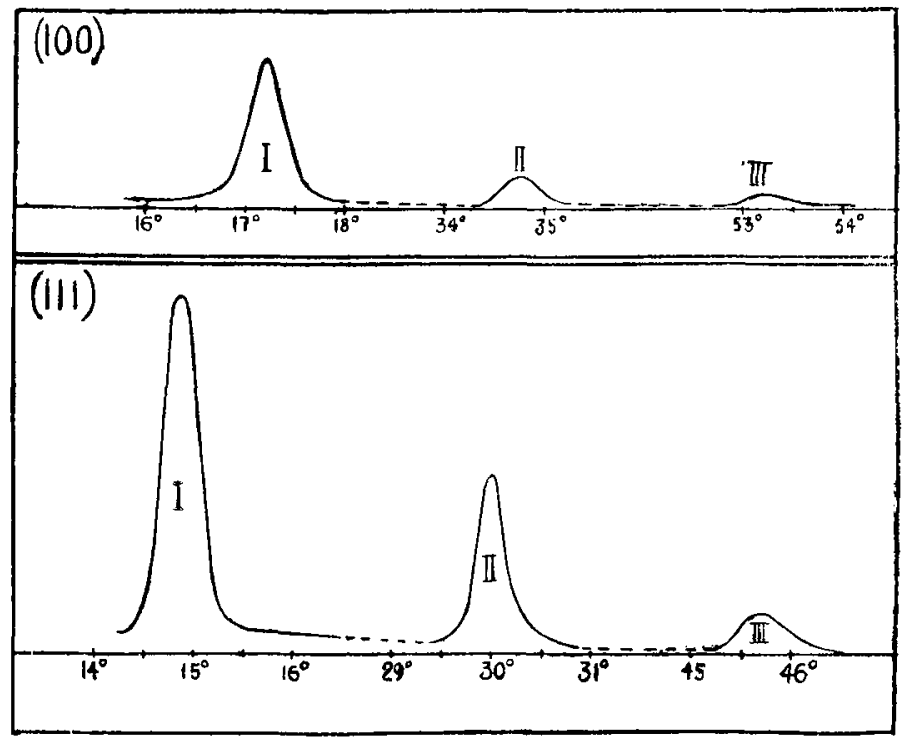

Rh line observed with the narrow slit, and in the table is given the glancing angle $\theta$ for the first order spectrum, the grating constant $d$, and the relative intensities of spectra of Jifferent orders. 


\begin{tabular}{|c|c|c|c|c|c|}
\hline \multirow{2}{*}{$\begin{array}{l}\text { Crystal } \\
\text { plane. }\end{array}$} & \multirow{2}{*}{$\theta_{1}$. } & \multirow{2}{*}{$d$. } & \multicolumn{3}{|c|}{ Relative Intensity. } \\
\hline & & & 1. & 2. & 3 order. \\
\hline$(100)$ & $8^{\circ} 36^{\prime}$ & $2.03010^{-8}$ & $1 \cdot 00$ & $0 \cdot 25$ & 0.07 \\
\hline (110) & $12^{\circ} 11^{\prime}$ & 1.438 & & Not 0 & red. \\
\hline (111) & $7^{\circ} 27^{\prime}$ & $2 \cdot 341$ & 1.00 & $0 \cdot 49$ & $0 \cdot 10$ \\
\hline
\end{tabular}

The faces (100) and (111) show a normal'variation of intensities, with the intensity rapidly decreasing with increasing order.

For the ratio of the grating constants we get

$$
\left.\left.\begin{array}{l}
\frac{d_{111}}{d_{100}}=1 \cdot 1533 \\
\frac{2}{\sqrt{3}}=1 \cdot 1547
\end{array}\right\} \begin{array}{l}
\frac{d_{111}}{d_{100}}=\frac{2}{\sqrt{ } 3} \\
\frac{d_{110}}{d_{100}}=0.7085 \\
\frac{1}{\sqrt{2}}=0.7071
\end{array}\right\} \begin{aligned}
& \frac{d_{110}}{d_{100}}=\frac{1}{\sqrt{2}} \\
& .
\end{aligned}
$$

These are the well-known ratios, which belong to the facecentred cubic lattice* (fig. 2). For if the side of the smallest cube with one atom in each corner is $2 a$, then we shall have

$$
d_{100}=a, \quad d_{110}=\frac{a}{\sqrt{2}}, \quad d_{111}=\frac{2 a}{\sqrt{3}} .
$$

Thus the ratios of the grating constants are explained from the face-centred lattice. This arrangement would further explain the normal distribution of intensities, as all point planes parallel to one of the faces examined should be identical and equidistant.

To put the lattice to a final test we shall calculate from observations the number $(n)$ of atoms which are associated with a cube of side $d_{100}$.

In the volume of the whole cube lattice with side $2 a$ (fig. 2) there are 4 atoms, and in the cube with a side $a=d_{100}$ there should be $\frac{1}{2}$ atom on an average.

For the number $n$ we get

$$
n=\frac{\rho}{\mathrm{A}} \mathrm{N} d_{100}^{3} \text {. }
$$

* W. H. Bragg and W. L. Bragg, Proc. Roy. Soc. vol. lxxxix. p. 281. 
Fig. 2.

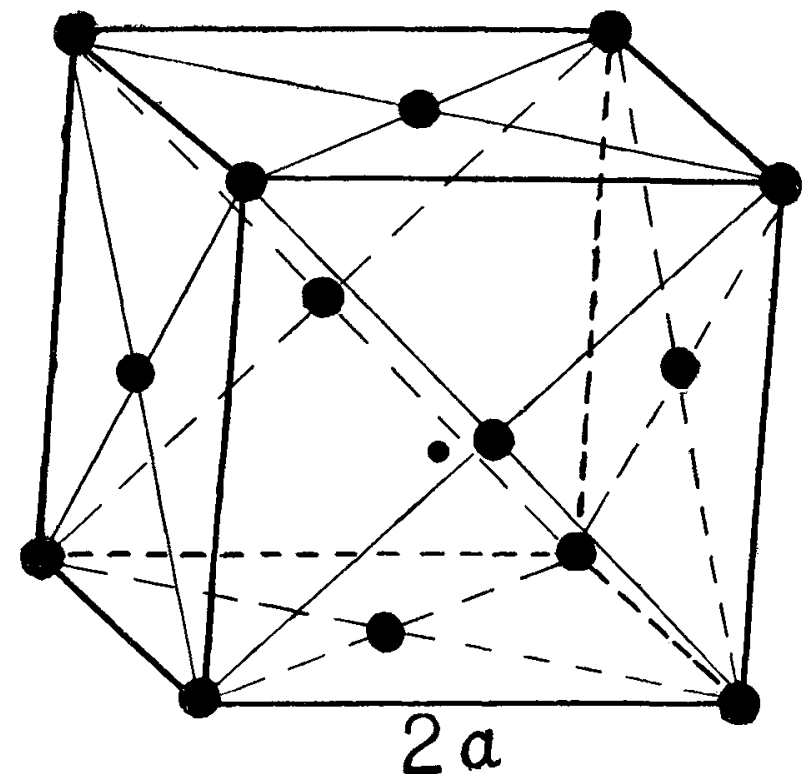

$\rho$ is the density of silver $(10 \cdot 50)$ and $A$ the atomic weight (107.93). $\quad \mathrm{N}$ is the number of atoms in a gramme equivalent $\left(61.5 \times 10^{22}\right)$, and $d_{100}$ is given in the table. Inserting these values,

$$
n=0.50002 \text {, or } \frac{1}{2} \text {. }
$$

Thus the face-centred cubic lattice explains the whole series of experiments, and we come to the conclusion that the atoms in the silver crystals are arranged in the simple face-centred lattice.

'The arrangement is the same as that previously found by W. L. Bragg for copper crystals *.

In conclusion, I wish to thank Professor W.H. Bragg and Mr. W. L. Bragg for valuable information with regard to the methods of the crystal analysis, Professor W. C. Brögger for his kindness in lending me the crystals and the goniometer on which the Röntgen-ray spectrometer was mounted, and Professor V. Goldschmidt for helpful advice with regard to nrystal work in general. Finally, my thanks are due to Mr. Harald K. Schjelderup for his assistance in making the readings.

Christiania, Oct. 20, 1915.

* W. L. Bragg, "On the Crystalline Structure of Oopper," Phil. Mag. vol xxviii. p. 355 (1914). 